\title{
Estimation Load Forecasting Based on the Intelligent Systems
}

\author{
Hanan A.R. Akkar \\ Wissam H. Ali \\ Department of Electrical Engineering, University of Technology, Baghdad, IRAQ \\ hnn_aaa@yahoo.com \\ wisamas1976@yahoo.com
}

http://doi.org/10.29194/NJES21020285

\begin{abstract}
:
The daily peak load forecasting for the next day is the basic operation of generation scheduling. The approach of using ANN methodology alone is limited which has generated interest to explore hybrid system. In this paper a search of genetic programming to a short term load forecasting is presented. A genetic architecture with the fitness normalization has been used to find as optimum data peak load of Baghdad city. The optimize data applied to the ANN to be trained and tested to estimate the daily peak load of Baghdad city. Different cases for load forecasting are considered with the aid of MATLAB 7 package to get the estimation of the next day. So an improvement method of genetic optimization is proposed to get a better solution for the load estimation rather than artificial neural network.
\end{abstract}

Keyword: Short term Load Forecasting, Artificial Intelligent AI, Neural network, Genetic

\section{Introduction}

The main objective of power system forecasting is to enable in any time on adaptation between demand and generation. This adaptation must consider load and generation characteristic and possible paths in transmission and distribution network to supply energy to consumer [1].

Two functions are very important in load estimation. The first is short term load forecasting such that predicating from hour to days. The second is long term forecasting where the load will be estimated month to year[2].

The research approach of short term load forecasting (STLF) can be divided into two categories: statistical and artificial intelligent methods. In statistical method (multiple linear regression, stochastic time series, general exponential smoothing state space and etc...) equation can be obtained showing the relationship between load and relative forecasting after training the historical data. While artificial intelligent methods try to imitate human being way of thinking and reasoning to get knowledge from the past experience and forecast the future load [3]. In this paper combinations of intelligent system have been used (ANN and GA).
Using more than on AI methods would increase the ability of these methods.

The most popular ANN architecture for load forecasting is back propagation. This network uses continuously values function and supervised learning. The ANN used in this work to predicate the daily peak load va1ue.

GA operates on populations of string, with the string coded to represent some underlying parameters set. Reproduction, crossover and mutation are applied successive string population to create a new string population [4]. . In this work GA approach is used to find the optimum value from the input vectors.

\section{Load Estimation}

Short-term forecasting being one of the most proposed design based on perceptron network Multi-layer perceptron (MLP) [5]. The attraction of MLP has been explained by the ability of the network to learn complex relationships between input and output pattern which would be difficult to model with conventional algorithm's methods. The main objective of short term load estimation is to expect hourly load, one day or even one week beforehand, so it necessary for the future operational planning of power system [6].

In this models, input to the network with optimize are globally present and past load values and outputs are future load 'value. The networks are generally present and past load values and outputs are future load values. The network trained using realload data from the past.

Generally the load of an electric utility is composed of different consumption units. A large part of electricity is consumed by industrial activities. Another part is of course used by private people informs of heating, lighting, cocking, laundry... etc [7]. Also many services offered by society demand electricity as an example street lighting real way traffic...etc. As far as electrical power system is concerned there has been a need to find out the future load in advance. Load estimation has been the central integral process, throughout planning and operation of electric utilities.

Economic and reliable operation of an electric utility power system depends to a significant extent on the accuracy of the load forecast. The daily peak load is an indication of 
many factors that have a direct influence on its value, the determination at these factors is very important since they give the system operator a good idea about the expected value of the peak load from day to day. The operator can perform unit commitment programs, economic load dispatch, and energy generation [2].

\section{Genetic algorithm for load estimation optimization}

Genetic algorithm is surpassing their more traditional cousins in the quest for robustness, so GA must differ in some very fundamental way [8].

In compare with artificial networks, these networks as brief models of the Intelligentsystem: It is highly interconnected neural computing elements that have the ability to response-to the input to adapt to the environment.

The genetic algorithm have high robustness than artificial neural network by finding the solution of optimization problems it can be describe in brief as follows [10].

First the algorithm generator and one population of chromosome from a population according to their fitness function after that a crossover probability. Make the crossover the parent to find a new offspring (child).

If crossover is performed offspring is deferent from their parents, then mutate new offspring at each locus or the point in chromosome take the result to place new offspring in the new population. Using the new generating children for more than runs of the algorithm, finally if the end condition is satisfied. Then end and return to best solution in current population $[10,11]$. The system load is the sum of all the consumers' load at the same time. The objective of system STLF is to forecast the future system load. Good understanding of the system characteristics helps to design reasonable forecasting models and select appropriate models in different situations [8].

Regression is one of most widely used statistical techniques. For load forecasting regression methods "'are usually employed to model the relationship of load consumption and other factors such as weather, day type and customer class [12].

A multi-variable regression can be written as $k(t)=b_{0}+\sum_{j=1}^{m} b_{j} t^{j}+g(t)$

Where $\mathrm{K}(\mathrm{t})$ is the peak load at time $\mathrm{t}, \mathrm{b}_{0}$ and $b_{j}$ are the regression coefficient which have relationship with $\mathrm{K}(\mathrm{t})$ at time $\mathrm{t}$ and $\mathrm{g}(\mathrm{t})$ is the gradual load. Form the above equation the calculation of gradual autocorrelation function $\mathrm{RF}$ at different time $\mathrm{t}$ can be finding as [13]:

$$
R F=\frac{\sum_{t=j+1}^{n} w_{j} w_{t}}{\sum_{t=1}^{n} w_{j}^{2}}
$$

So know RF is gradual autocorrelation at time $t$ and $\mathrm{w}$ is the estimated residual [14].

This function is the method of optimization the input data to forecast the peak load. In this paper a proposed optimization method is presented using the genetic algorithm by replacing the RF function with one of the fitness function for GA to present a high performance of optimization input data. Fig. (1) shows the proposed hybrid system.

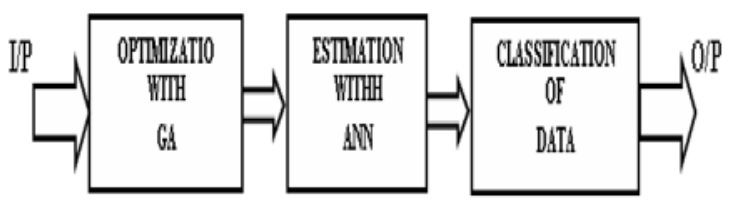

Figure 1: The hybrid system process

\section{Model description}

In this paper two models have been proposed to estimate the next day peak load. The input parameters to the structure contains the forecasted maximum temperature in the three different areas (north, middle, south), for the day being conducted. There corded maximum 'temperature of the previous day in the three areas, and the recorded maximum temperature and peak load in the past ten days with the same load pattern like the forecasted day the total number of neurons are (46) neuron in the input layer for the two models. Load shape values, can be affected by weather or seasonal variations or even weekly, monthly, and annual cycle. The input-vectors sorted according to the four seasons: The distribution of months over the' seasons decided depending upon the relation between the peak load demand and weather conditions.

(1) Winter season from $1^{\text {st }}$ Mar. to $30^{\text {th }}$ Feb.

(2) Spring season from $1^{\text {st }}$ May to $30^{\text {th }}$ Sep.

(3) Summer season from $1^{\text {st }}$ May to $30^{\text {th }}$ Sep.

(4) Autumn season from $1^{\text {st }}$ Oct. to $30^{\text {th }}$ Nov. The existence of bad data in historical load curve affects the precision of load forecasting result.

\subsection{First Model}

First model uses artificial neural network. The network construction consist of input layer, which represents one hidden layer with (60) neuron and output layer with (1) neuron which represents peak load to forecast the next day peak load for the four seasons. Neural network deals with numbers between (0-1) , therefore the data are normalized using the equation:

$$
Z_{\text {nor }}=\frac{z-z_{\min }}{z_{\max }-z_{\min }}
$$

Where $\mathrm{Z}_{\text {nor }}=$ normalized value,

$\mathrm{Z}_{\text {min }}=$ minimum value and

$\mathrm{Z}_{\max }=$ maximum value 


\subsection{The Second Model (GA-ANN)}

The second model uses the technique of combining Genetic Algorithm and Artificial Neural Network. GA approach is employed to find the optimum values of the state vector $z$ (input data). Fitness function is normalized with range between (0-1).The fitness function adopted is:

$$
f=\frac{1}{1+k \sum_{j=1}^{m}|z(i, j)|}
$$

Where $\mathrm{z}(\mathrm{i}, \mathrm{j})$ is the input matrix , $\mathrm{k}$ is a scaling vector. After applying data to

GA they apply to ANN. The construction of ANN changes due to that, input layer, one hidden layer $(24 ;-24,28,25)$ neurons for winter, spring, summer and autumn respectively and(1) neuron in the output layer to forecast the next day peak load for the four seasons.

\section{Results Evaluation}

To test the performance of the network the Relative Percentage Error (RPE) is used to defined as follows:

$$
R P E=\left|\frac{\text { actual }_{i}-\text {-forecasted }_{i}}{\text { actual }_{i}}\right| \times 100 \ldots \text { (5) }
$$

Where actual is the actual load of the same I and forecast is the forecasted load of that sample. Test would require the use of data at all the year, but must not be carried with same data used in the training set.

\section{Comparison \& Irison of ANN Results With GA-ANN}

The final accuracy of the forecasted process depends on the model selection and the accuracy of estimated parameters. The simulation results are presented in tables (1),(2), (3) and (4) for winter, spring, summer and autumn respectively.

Table 1: winter testing result for two model.

\begin{tabular}{|c|c|c|c|}
\hline $\begin{array}{c}\text { NO. of } \\
\text { tested } \\
\text { patterns }\end{array}$ & $\begin{array}{c}\text { Actual } \\
\text { load } \\
\text { Value } \\
(\mathbf{M W})\end{array}$ & $\begin{array}{c}\text { Estimated } \\
\text { loads value of } \\
\text { ANN }(\mathbf{M W})\end{array}$ & $\begin{array}{c}\text { Estimated } \\
\text { load value } \\
\text { of } \text { ANN } \\
\text { \&GA }(\boldsymbol{M W})\end{array}$ \\
\hline 1 & 1821 & 1859 & 1812 \\
\hline 2 & 1829 & 1803 & 1847 \\
\hline 3 & 1848 & 1928 & 1817 \\
\hline 4 & 1850 & 1956 & 1779 \\
\hline 5 & 1871 & 2094 & 1893 \\
\hline 6 & 1979 & 1788 & 1991 \\
\hline 7 & 2041 & 1922 & 2043 \\
\hline 8 & 1940 & 1987 & 1899 \\
\hline 9 & 1950 & 1865 & 1907 \\
\hline 10 & 1960 & 1828 & 1895 \\
\hline 11 & 1965 & 1877 & 1954 \\
\hline 12 & 1976 & 1955 & 1997 \\
\hline 13 & 2008 & 2026 & 2007 \\
\hline 14 & 1990 & 1759 & 2020 \\
\hline
\end{tabular}

\begin{tabular}{|l|l|l|l|}
\hline 15 & 1980 & 1984 & 1921 \\
\hline 16 & 1979 & 2044 & 1979 \\
\hline 17 & 1885 & 1829 & 1928 \\
\hline 18 & 1870 & 1807 & 1938 \\
\hline 19 & 1963 & 1964 & 1963 \\
\hline 20 & 1746 & 1752 & 1850 \\
\hline
\end{tabular}

Table 2: spring testing result for two model

\begin{tabular}{|c|c|c|c|}
\hline $\begin{array}{c}\text { NO. of } \\
\text { tested } \\
\text { patterns }\end{array}$ & $\begin{array}{c}\text { Actual } \\
\text { load } \\
\text { Value } \\
(\mathbf{M W})\end{array}$ & $\begin{array}{c}\text { Estimated } \\
\text { loads } \\
\text { Value of } \\
\text { ANN } \\
(\mathbf{M W})\end{array}$ & $\begin{array}{c}\text { Estimated } \\
\text { load } \\
\text { Value of ANN } \\
\mathbf{8} \text { GA } \\
(\mathbf{M W})\end{array}$ \\
\hline 1 & 1432 & 1614 & 1426 \\
\hline 2 & 1437 & 1423 & 1439 \\
\hline 3 & 1436 & 1456 & 1538 \\
\hline 4 & 1428 & 1423 & 1432 \\
\hline 5 & 1431 & 1431 & 1439 \\
\hline 6 & 1434 & 1520 & 1433 \\
\hline 7 & 1438 & 1441 & 1435 \\
\hline 8 & 1445 & 1347 & 1447 \\
\hline 9 & 1440 & 1385 & 1438 \\
\hline 10 & 1470 & 1381 & 1458 \\
\hline 11 & 1432 & 1355 & 1450 \\
\hline 12 & 1415 & 1467 & 1402 \\
\hline 13 & 1408 & 1396 & 1435 \\
\hline 14 & 1397 & 1507 & 1420 \\
\hline 15 & 1407 & 1544 & 1420 \\
\hline 16 & 1400 & 1538 & 1430 \\
\hline 17 & 1410 & 1560 & 1433 \\
\hline 18 & 1444 & 1426 & 1444 \\
\hline 19 & 1439 & 1523 & 1447 \\
\hline 20 & 1450 & 1518 & 1447 \\
\hline
\end{tabular}

Table 3: Summer testing result for two model

\begin{tabular}{|c|c|c|c|}
\hline $\begin{array}{c}\text { NO. of } \\
\text { tested } \\
\text { Patterns }\end{array}$ & $\begin{array}{c}\text { Actual } \\
\text { loads } \\
\text { Value } \\
(\boldsymbol{M W})\end{array}$ & $\begin{array}{c}\text { Estimated } \\
\text { loads } \\
\text { Value of } \\
\text { ANN } \\
(\boldsymbol{M W})\end{array}$ & $\begin{array}{c}\text { Estimated } \\
\text { loads } \\
\text { Value of } \\
\text { ANN \& GA } \\
(\mathbf{M A})\end{array}$ \\
\hline 1 & 1540 & 1352 & 1540 \\
\hline 2 & 1555 & 1493 & 1486 \\
\hline 3 & 1755 & 1768 & 1721 \\
\hline 4 & 1818 & 2010 & 1809 \\
\hline 5 & 1861 & 1849 & 1861 \\
\hline 6 & 1880 & 1897 & 1905 \\
\hline 7 & 1932 & 1960 & 1990 \\
\hline 8 & 1942 & 1962 & 1892 \\
\hline 9 & 1970 & 2099 & 1899 \\
\hline 10 & 2017 & 2025 & 2022 \\
\hline 11 & 2056 & 2162 & 2068 \\
\hline 12 & 2095 & 2181 & 2092 \\
\hline 13 & 2135 & 2167 & 2147 \\
\hline 14 & 1979 & 1980 & 2061 \\
\hline 15 & 1950 & 1930 & 1952 \\
\hline 16 & 1850 & 1887 & 1904 \\
\hline 17 & 1830 & 1879 & 1831 \\
\hline 18 & 1772 & 1842 & 1734 \\
\hline 19 & 1768 & 1745 & 1748 \\
\hline 20 & 1709 & 1679 & 1637 \\
\hline
\end{tabular}


Table 4: autumn testing result for two model.

\begin{tabular}{|c|c|c|c|}
\hline $\begin{array}{c}\text { NO. of } \\
\text { tested } \\
\text { Patterns }\end{array}$ & $\begin{array}{c}\text { Actual } \\
\text { load } \\
\text { Value } \\
\text { (MW) }\end{array}$ & $\begin{array}{c}\text { Estimated } \\
\text { load } \\
\text { Value of } \\
\text { ANN } \\
\text { (MW) }\end{array}$ & $\begin{array}{c}\text { Estimated } \\
\text { Ioad } \\
\text { Value of ANN } \\
\text { \& GA } \\
(\boldsymbol{M W})\end{array}$ \\
\hline 1 & 1580 & 1537 & 1565 \\
\hline 2 & 1560 & 1571 & 1572 \\
\hline 3 & 1549 & 1582 & 1502 \\
\hline 4 & 1543 & 1491 & 1543 \\
\hline 5 & 1537 & 1463 & 1476 \\
\hline 6 & 1521 & 1551 & 1531 \\
\hline 7 & 1519 & 1602 & 1519 \\
\hline 8 & 1506 & 1580 & 1512 \\
\hline 9 & 1482 & 1523 & 1467 \\
\hline 10 & 1456 & 1537 & 1456 \\
\hline 11 & 1435 & 1436 & 1516 \\
\hline 12 & 1323 & 1360 & 1323 \\
\hline 13 & 1335 & 1355 & 1338 \\
\hline 14 & 1388 & 1499 & 1360 \\
\hline 15 & 1474 & 1418 & 1474 \\
\hline 16 & 1605 & 1687 & 1605 \\
\hline 17 & 1692 & 1682 & 1717 \\
\hline 18 & 1725 & 1763 & 1760 \\
\hline 19 & 1809 & 1790 & 1792 \\
\hline 20 & 1812 & 1849 & 1812 \\
\hline & & & \\
\hline
\end{tabular}

Table (5): summarizes the difference between the two models in the number of iteration for the simulation process.

\begin{tabular}{|c|c|c|}
\hline Items & $\begin{array}{c}\text { NO. of Epoch } \\
\text { of ANN }\end{array}$ & $\begin{array}{c}\text { NO. of Epoch } \\
\text { of ANN \& GA }\end{array}$ \\
\hline Winter & 3500 & 6 \\
\hline Spring & 810 & 4 \\
\hline Summer & 25000 & 51 \\
\hline Autumn & 21000 & 7 \\
\hline
\end{tabular}

The GAs approach presented in this optimum values of the state vector which minimizes the ' absolute summation of the forecasted vector in order to emphasize the best string and speed up convergence 'of iteration procedure.

Fig.(2), Fig.(3), Fig.(4) 'and Fig.(5) winter, spring, summer and autumn respectively show" the Relative Percentage Error (RPE) for the two models.

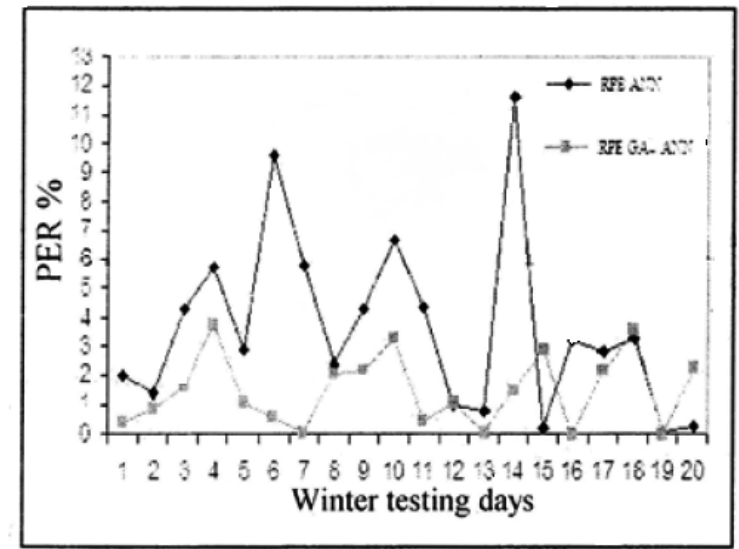

Figure 2: RPE for winter season.

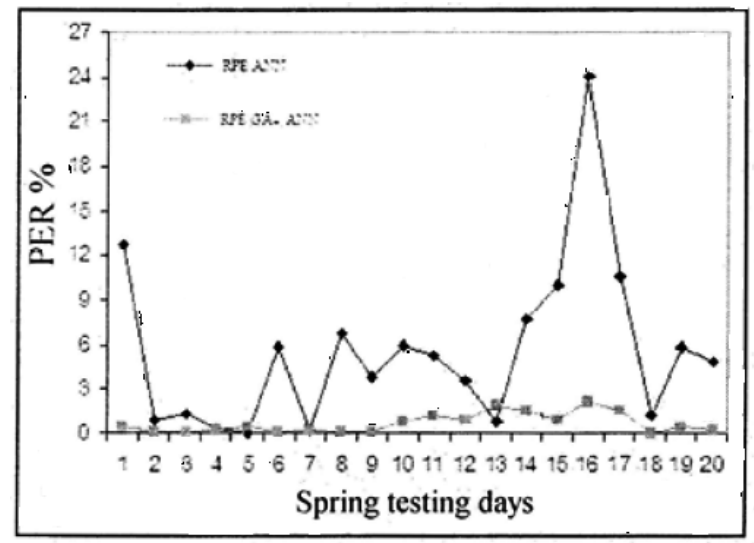

Fig 3 RPE for spring season

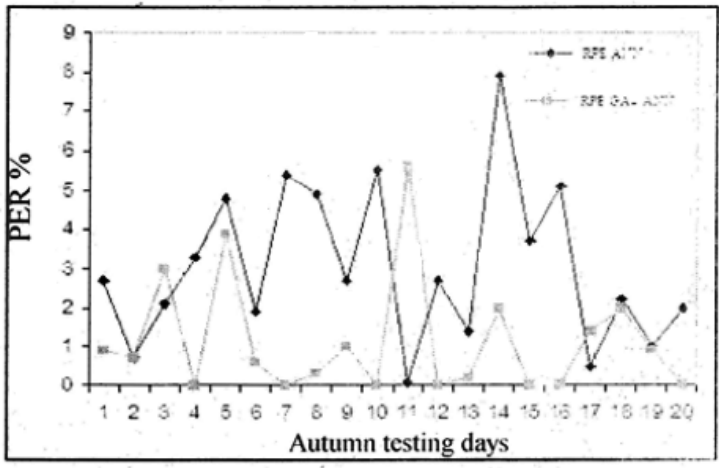

Fig 4 RPE for Autumn season

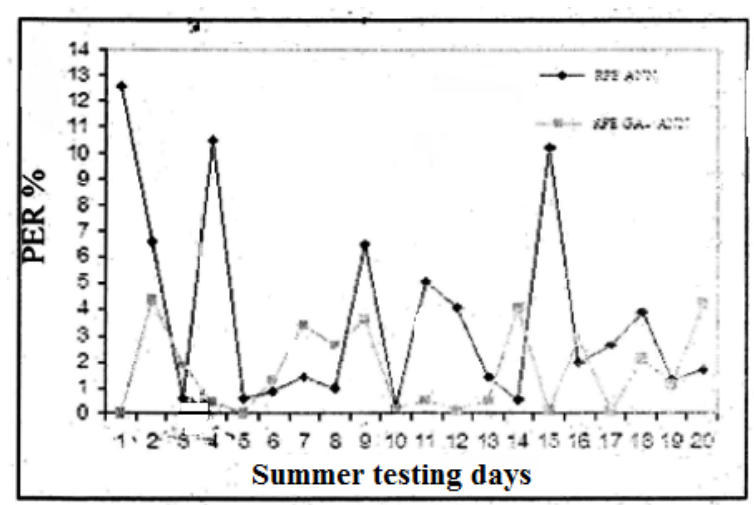

Fig 5 RPE for summer season 
Table (6): Summarizes the difference between two model proposed in over all percentage error for the whole year

\begin{tabular}{|c|c|c|}
\hline Item & $\begin{array}{c}\text { Percentage } \\
\text { error of ANN }\end{array}$ & $\begin{array}{c}\text { Percentage error } \\
\text { of ANN \& GA }\end{array}$ \\
\hline Winter & 3.63 & 1.5 \\
\hline Spring & 5.59 & 0.7 \\
\hline Summer & 3.69 & 1.7 \\
\hline Autumn & 3.0 & 1.1 \\
\hline $\begin{array}{c}\text { Average } \\
\text { error }\end{array}$ & 3.97 & 1.2 \\
\hline
\end{tabular}

Fig (6), ,Fig (7), Fig.(8) and Fig. (9) shows the training curve using the first model for winter, spring, summer and autumn respectively. Fig(10) Fig(11 ),Fig(12)and Fig.(13) show the training curve using the second model for winter, spring, summer and autumn respectively.

\section{Conclusions}

In the first an improvement method in the first an improvement method of genetic optirf1ization is proposes to get a better solution for the load estimation rather than artificial neural network. Load forecasting is an important component of power system energy management system;1 But the global method not introduced a solution for many problems in. future load demand from this research it can be seen that optimizing the input data with GA will reduce the estimation error from $70 \%$ to $87 \%$ than sin ANN. The integration of two intelligent allows the computer system to solve problems and to find solutions. Noting that one of the techniques alone could not get the use of two techniques to get her allow limitations be covered always using each one's better characteristic. Combing ANN with GA would reduce the PER for the forecasted daily peak load and greatly reduce the number of iteration of the artificial neural network epoch as shown in the result and minimize the SSE.

\section{References}

[1]- H. G. Aptingo, A.c. Zambr De Souza, G. Lambert- Torres and A.P. Alves Da Silva, "Difference Between Regular and Ditermistic Chaos Brocesses Based Data", Electric power systems research, Vol. 56,2000.

[2] M. Hisham, C. A. Mount, "Buildin A 'Quasi Optimal' Neural Network 10' Solve the Short-Term Load Forecasting Problem" IEEE Transaction on power System, Vol. 12, No.4, 1997

[3] J. 'Yang, " Power System Short Term Load Forecasting", Ph.D. Electrical and information Dep. In University of Darmstadt Technology, China, 2006.

[4] David. E. Goldberg "Genetic Algorithms in Search, Optimization, and Machine Learning", McGraw-Hill, 1989.

[5] E. Savelieva, A. Kravestski, "Application of MLP and Stochastic Simulation for Electricity Load Forcasting " in Russia", ESANN2000, pp . 413-418, 2000.

[6] dong Ho, Y.Yih Hus" Short Term Load Forecasting using A Multilayer Neural Network with an Adaptive learning: Algorithm", Transaction of Power 7Ystem, Vol. 7, No. 1, 1992.

[7] A. S. Aifuhaud. M. A. El-Sayed "Cascaded Artificial Neural Network For Short-Term Load forcasting", IEEE Transaction on power System, Vol. 12, No.4, 1997

[8] A. UI Asar, S. UI hassanain,"A Multiagent Approach to Short Term Load forecasting Problem", International Journal of Intelligent Control and Systems, Vol. 10, No.1, 2005.

[9] S. D. Hssan, "Design and Training of Artificial Neural Network by Using Genetic Algorithm", Thesis, University of Technology, 2001

[10] L. Krichen, H. HadjAbdallah, "Genetic Algorithms for, OptimalReactive Power Compensation ofaPower System with Wind GeneratorsBased on Artificial Neural Networks", 1. Electrical System, Vol. 3. No. 12.2007

[11] G. A. Bakare, U.O. Aliya, "Genetic Algorithm Based EconomicDispatch with Application toCoordination of Nigerian ThermalPower Plant", IEEE Transaction 07803 - 9156,2005.

[12] K. M. El-Naggar, K.A. AlRumaih," Electric Load Forecasting using Genetic Based Algorithm, Optimal Filter Estimator and Least Error Square Technique Comparative Stud Proceeding of World Academy of Jtience, Engineering and Technology, Vol. 6, ISSN ,1307- 6884,June 2005.

[13] wl3. Dai, P.H. Zou, C.X. Yan, "Research on Short -Term Load Forecasting of the Thermoelectric Boiler Based on Dynamic RBF Neural Network", HVDC Technology for Energy Efficiency, Vol. IV-6-5,ICEBO 2006.

[14] A. Mizutani, T. Yukawa, K. Numa, Y. Kuze ,T. Iizaka, T. Yamagishi, T. Matsui, and Y. Fukuyama, " Improvement of Input Output Correlations of Electric Power Load Forecasting by Scatter Search ",IEEE Intelligent System, Application2006. 


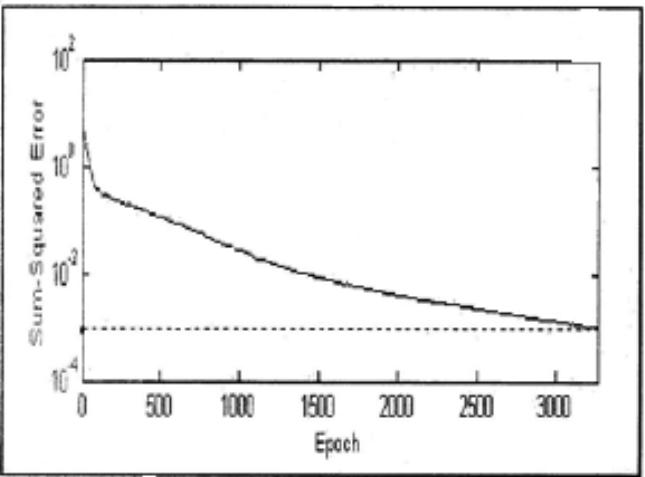

Fig.(6) Training curve for winter season for the first model.

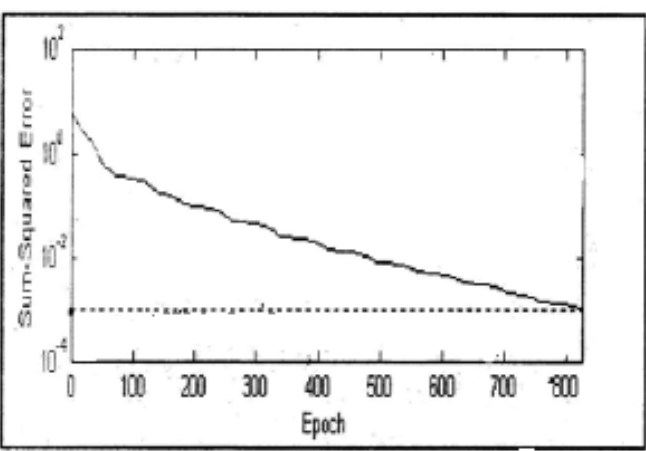

Fig.(7) Training curve for spring season for the first model.

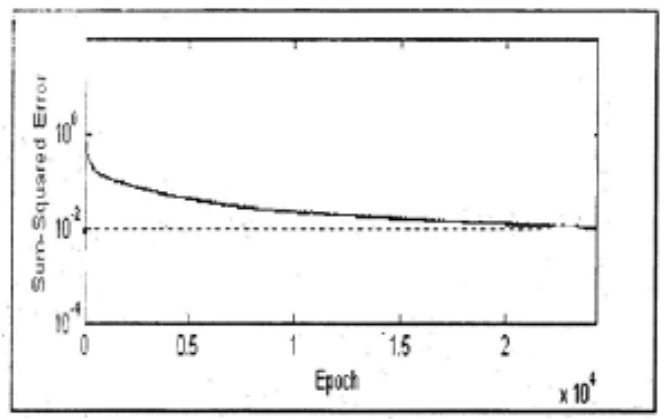

Fig.(8) Training curve for summer season for the first model.

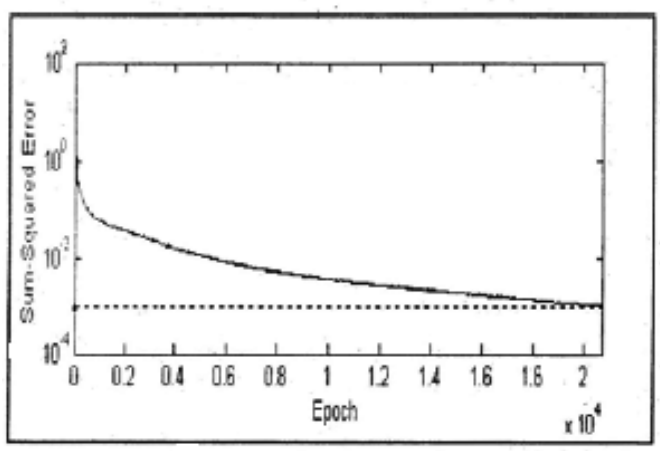

Fig.(9) Training curve for autumn season for the first model.

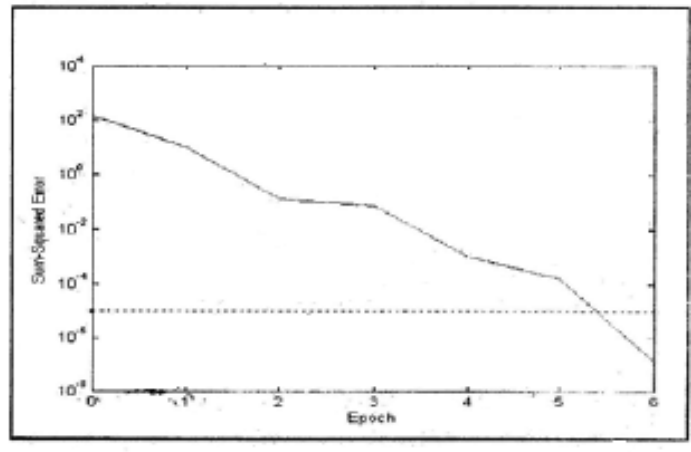

Fig.(10) Training curve for winter season for the second model.

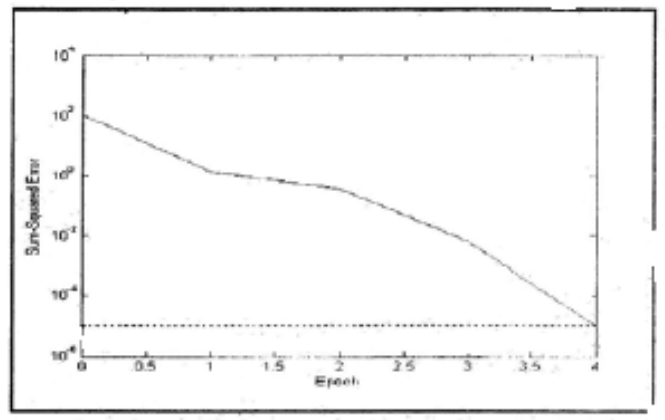

Fig.(11) Training curve for spring season for the second model.

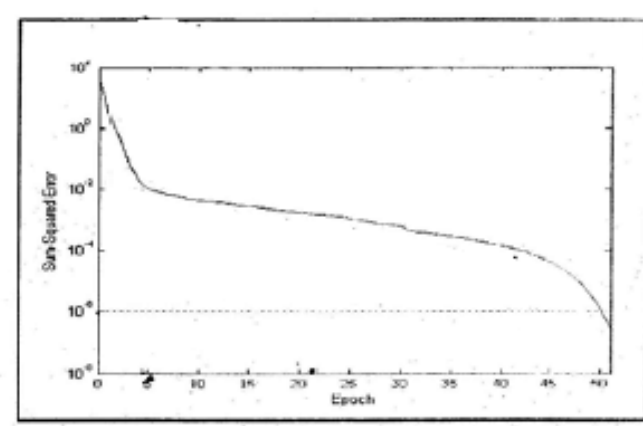

Fig.(12) Training curve for summer season for the second model.

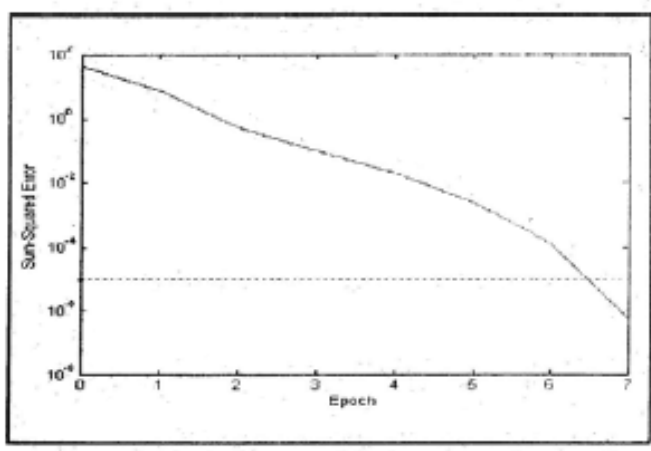

Fig.(13) Training curve for autumn season for the second model. 


\section{تخمين احمال القدره بالاعتماد على الأنظمة الذكية

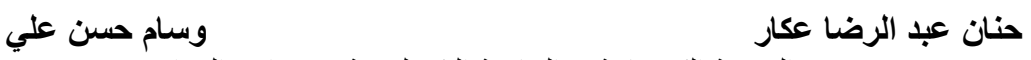 \\ قسم الهنسة الكهربائية ـ الجامعة التكنولوجية - بغداد ـ العراق}

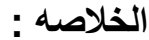

التتبؤ اليومي لأحمال الذروة لليوم النالي هو التثغيل الأساسي لجدولة التوليد. إن نهج استخدام منهجية ANN وحده محدود مما أدى إلى

اهتمام باستكشاف النظام المختلط. في هذه البحث ، يتم عرض البرال البرمجة للتتبؤ بالحمل قصبر الددى بالاعتماد على النظريه الجينيه

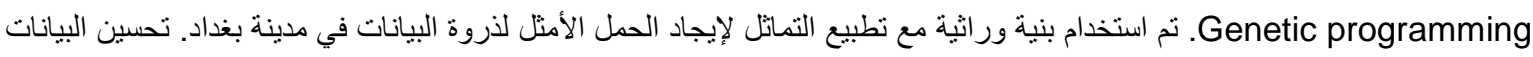
المطبقة على شبكة (ANN) لتدرييها واختبارها لتقدير حمل الذروة اليومي لمدينة بغداد. ينم النظر في حالات مختلفات للتنبؤ بالأحمال

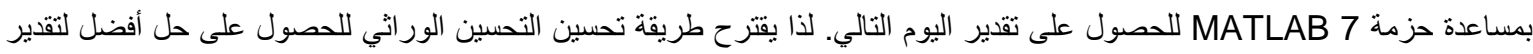
الحمل بدلاً من الثبكة العصبية الاصطناعية. 